\title{
Hip protectors are cost-effective in the prevention of hip fractures in patients with high fracture risk
}

Citation for published version (APA):

de Bot, R. T. A. L., Veldman, H. D., Witlox, A. M., van Rhijn, L. W., \& Hiligsmann, M. (2020). Hip protectors are cost-effective in the prevention of hip fractures in patients with high fracture risk. Osteoporosis International, 31(7), 1217-1229. https://doi.org/10.1007/s00198-019-05252-8

Document status and date:

Published: 10/02/2020

DOI:

10.1007/s00198-019-05252-8

Document Version:

Publisher's PDF, also known as Version of record

Document license:

Taverne

\section{Please check the document version of this publication:}

- A submitted manuscript is the version of the article upon submission and before peer-review. There can be important differences between the submitted version and the official published version of record. People interested in the research are advised to contact the author for the final version of the publication, or visit the DOI to the publisher's website.

- The final author version and the galley proof are versions of the publication after peer review.

- The final published version features the final layout of the paper including the volume, issue and page numbers.

Link to publication

\footnotetext{
General rights Owners
rights.

- You may freely distribute the URL identifying the publication in the public portal. please follow below link for the End User Agreement:

www.umlib.nl/taverne-license

Take down policy

If you believe that this document breaches copyright please contact us at:

repository@maastrichtuniversity.nl

providing details and we will investigate your claim.
}

Copyright and moral rights for the publications made accessible in the public portal are retained by the authors and/or other copyright owners and it is a condition of accessing publications that users recognise and abide by the legal requirements associated with these

- Users may download and print one copy of any publication from the public portal for the purpose of private study or research.

- You may not further distribute the material or use it for any profit-making activity or commercial gain

If the publication is distributed under the terms of Article $25 \mathrm{fa}$ of the Dutch Copyright Act, indicated by the "Taverne" license above, 


\title{
Hip protectors are cost-effective in the prevention of hip fractures in patients with high fracture risk
}

\author{
R.T.A.L. de Bot ${ }^{1,2}$ • H.D. Veldman ${ }^{2,3}$ - A.M. Witlox ${ }^{1}$ - L.W. van Rhijn ${ }^{1} \cdot$ M. Hiligsmann ${ }^{2}$
}

Received: 5 September 2019 / Accepted: 29 November 2019/Published online: 10 February 2020

(C) International Osteoporosis Foundation and National Osteoporosis Foundation 2020

\begin{abstract}
Cost-effective preventive interventions are necessary for tackling the increasing number of hip fractures, which are frequently occuring as a serious consequence of osteoporosis. Several interventions have been available for preventing and treating osteoporosis. The aim of this study was to systematically review and critically appraise studies that assessed cost-effectiveness of hip protectors for the prevention of hip fractures and to investigate the effects of age, gender and residence situation on costeffectiveness. A systematic review was conducted in order to identify economic evaluation studies examining the hip protector solely or compared to no treatment according to the Preferred Reported Items for Systematic Reviews and Meta-Analyses (PRISMA) statement. Synthesis of results was performed to observe trends between the studies. Methodological quality of the studies was assessed by the use of the Quality of Health Economic Studies (QHES) instrument. A total of 15 economic evaluation studies were included for analysis. The methodological quality was high in most studies (13/15). The hip protector was solely evaluated in three studies and within 12 other studies compared with no intervention. All studies that investigated the costeffectiveness in long-term care facilities revealed that hip protector use is a cost-effective strategy for the prevention of hip fractures in elderly. Cost-effectiveness was also observed in two studies that provided hip protectors in a geriatric hospital ward. Four studies included both community-dwelling residents and residents living in a long-term care facility in their study. These studies showed more variability regarding cost-effectiveness. One study did not report information regarding the residence situation of their cohort, but also observed cost-effectiveness. In conclusion, this review suggests that hip protectors are a costeffective approach in the prevention of hip fractures in populations with high risk of hip fractures especially in long-term care facilities and a geriatric ward in a hospital.
\end{abstract}

Keywords Cost-effectiveness $\cdot$ Hip fractures $\cdot$ Hip protectors $\cdot$ Osteoporosis

\section{Introduction}

Osteoporosis is a major public health problem that affects millions of people worldwide [1-3]. A frequent and serious consequence of osteoporosis is a hip fracture leading to high

R.T.A.L. de Bot

rtaldebot@gmail.com

1 Department of Orthopaedics, Maastricht University Medical Center, P. Debyelaan 25, NL-6202 AZ Maastricht, The Netherlands

2 Care and Public Health Research Institute (CAPHRI), Department of Health Services Research, Maastricht University, P.O. Box 616, NL-6200 MD Maastricht, The Netherlands

3 Department of Orthopaedic Surgery and Traumatology, Zuyderland Medical Center Heerlen, H. Dunantstraat 5, NL-6419 PC Heerlen, The Netherlands morbidity, excess mortality, substantial costs and decreased quality of life [2, 4-9]. As a consequence of an ageing population, the number of hip fractures is estimated to increase by $32 \%$ (615,316 to 814,747 cases) in Europe between 2010 and 2025 [10]. Several risk factors are known to predispose individuals to hip fractures, including: female gender, older age, a high number of comorbidities, low cognitive function, previous spine or hip fracture and poor neuromuscular function [8, 11-15]. Additionally, it is well described that patients in longterm care facilities have much higher fall rates compared with community-dwelling residents and that these falls more frequently lead to serious complications [16-18].

Preventive interventions are needed to reduce the number of hip fractures. Several interventions have been described to reduce the risk of hip fractures including regular exercise (e.g. muscle strengthening and balance trainings), drug treatments (e.g. calcium, vitamin D and antiresorptives/anabolics) and/or 
the use of hip protectors [19-23]. Since more than $90 \%$ of the hip fractures are the result of a fall $[24,25]$, hip protectors could be an interesting strategy/intervention for preventing hip fractures. Hip protectors are shields of hard plastic or soft foam that are processed in specially designed underwear leading to an immediate protective effect [26-29]. The force of impact is shunted or partly absorbed by the shield in case of a fall, which aims to prevent a fracture from occurring $[26,28$, 29]. The level of effectiveness of the hip protector has been a topic of debate for the last 15 years [23,30-34], indicated by the great amount of publications regarding this device, the variability in reported effectiveness ratios and the frequent systematic review updates [31-33]. Currently, the most recently updated Cochrane systematic review reports an $18 \%$ reduction of hip fractures by the use of hip protectors in long-term care facilities [23] and concludes that the effectiveness could even be higher with improved adherence and acceptance levels [23, 30, 35].

Given the increasing economic burden of hip fractures, there is a growing interest in cost-effective preventive interventions such as the hip protector. In recent years, several costeffectiveness studies on hip protectors in different populations have been published. However, to our knowledge, there is no systematic overview and critical assessment that solely evaluates the cost-effectiveness of the hip protector. Therefore, the aim of this study is to systematically review and critically appraise studies that assessed cost-effectiveness of hip protectors for the prevention of hip fractures. Furthermore, we aimed to investigate the effects of age, gender and residence situation, as being risk factors of a hip fracture, on hip protector cost-effectiveness.

\section{Materials and methods}

This systematic review was conducted according to the Preferred Reporting Items for Systematic Reviews and Meta-Analyses (PRISMA) guideline [36]. The search was conducted within PubMed/Medline, Embase, Econlit, Web of science and Cochrane library. The search consisted of a combination of several terms related to the disorder ('Hip fracture', 'Femoral neck fracture', 'Proximal femur fracture', 'Subtrochanteric fracture', 'Femur fracture', 'Fractured femur', 'Periprosthetic fracture'), the intervention ('Hip protector', 'Hip saver', 'Protecting trouser', 'Protector', 'Protective devices', 'Fall prevention', 'Protected fall', 'Protect', 'Underwear', 'Trouser', 'Pad', 'Pants') and the outcome ('Economic evaluation', 'Economic analysis', 'Economic', 'Health economics', 'Health technology assessment', 'HTA', 'Cost effectiveness', 'CEA', 'Cost effective', 'Cost utility', 'CUA', 'Cost benefit', 'CBA', 'Cost analysis', 'Costs' 'ICER' or 'ICUR'). No restrictions on language and publication date were applied to the search strategy. The initial search was performed on April 9th, 2019. Furthermore, reference lists and citations of the included studies were screened for additional studies.

Titles and abstract of the retrieved studies were first screened and studies reporting an economic analysis (i.e. cost-effectiveness, cost utility or clinical effectiveness and associated costs) of the hip protector were included. Subsequently, full-text article screening was done. Studies were included if the hip protector was solely evaluated (i.e. partial economic evaluation) or compared with other interventions (i.e. full economic evaluation). Another criterion for eligibility was that studies should report the results of the hip protector as solely preventive intervention, thus not as an addition of other preventive strategies. Only original scientific papers in academic English were included. Two reviewers (RdB and HV) conducted the initial search and study selection process independently and discrepancies were resolved by discussion and consultation of a third reviewer $(\mathrm{MH})$.

Relevant information was extracted including study characteristics (i.e. author, year of publication, journal) and study design (i.e. country, population, study perspective, model type, time horizon, outcome measure, valuation, year of valuation and discount rates). Furthermore, the main results in terms of outcomes and associated costs were collected including study population's characteristics, the incremental costeffectiveness ratios (ICER) in terms of cost per hip fracture prevented and/or cost per quality-adjusted life years (QALY) gained and the overall conclusion of each study including the used cost-effectiveness threshold. Subsequently, the data was reviewed to observe similarities and differences regarding the cost-effectiveness. Since previous studies investigated that hip protector effectiveness is influenced by residence status (i.e. long-term care facility or community-dwelling), age and gender, this was incorporated in reporting of the results $[23,30]$.

The methodological quality of the included studies was assessed by the use of the Quality of Health Economic Studies (QHES) instrument. The QHES is a validated quality scoring instrument, which was developed to evaluate health economic analyses and emphasize appropriate methods, valid and transparent results and comprehensive reporting of results in each study [37, 38]. The 16 items were scored with 'Yes' (reported) and 'No' (not reported). Each item is weighted with points and the total amount of points earned represents the methodological quality [37]. The possible score ranges between 0 (lowest quality) and 100 (highest quality). Additionally, the studies were grouped according to the following quartiles: extremely poor quality $(0-24)$, poor quality $(25-49)$, fair quality (50-74) and high quality (75-100) [39]. The data extraction process and quality assessment was independently executed by two reviewers (RdB and HV). Inconsistencies in data extraction or critical appraisal of the studies were resolved by discussion until consensus was reached. 


\section{Results}

\section{Study selection}

The initial search yielded 601 articles (Fig. 1). After title and abstract screening, 119 potential articles were identified. Of those, 53 duplicates were excluded leading to 66 articles for full-text assessment. During this full-text assessment, 51 articles were excluded. The majority of studies was excluded because they did not describe original research $(n=23)$, because they did not investigate the intervention of interest $(n=$ 13 ), or because they did not examine both outcome and associated costs $(n=9)$. Finally, a total of four studies was excluded because they investigated a multiprevention program without a distinction in results for hip protectors and two were not written in the English language. Therefore, a total of 15 articles were eligible for inclusion in this systematic review. No additional records were identified after screening of the reference lists and citations of the included studies.

\section{Study characteristics}

An overview of the study characteristics is presented in Table 1. The fifteen original economic studies regarding the hip protector were performed and published between 2000 and 2015. The studies were conducted in several countries including the USA $(n=4)$, Germany $(n=4)$, Canada $(n=3)$, the UK $(n=2)$, the Netherlands $(n=1)$

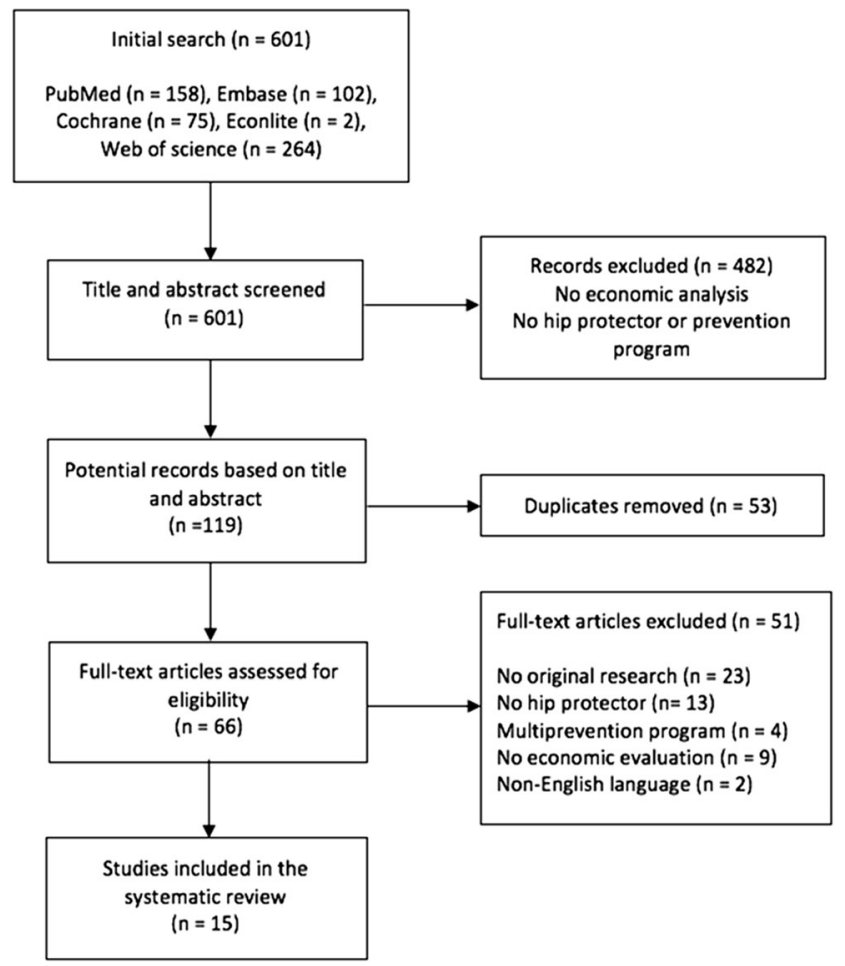

Fig. 1 Flowchart of the study selection process and Australia $(n=1)$. A societal perspective was used in five studies and in another five studies, a third party payer perspective. Two studies reported both perspectives [51, 53] one reported a hospital perspective [52] while two studies did not mention the used cost-perspective [40, 43]. The majority of the studies were model-based, whereas eight studies used a Markov model, and three studies used a decision tree. The remaining studies performed a trial-based economic evaluation [46, 47] or did not specifically report their study type but were on a mathematical basis $[40,50]$. A lifetime perspective was considered in eight studies, while one study limited their time horizon to 17 years since the low probability (i.e. $0.001 \%$ ) of survival after this timeframe within their population [51]. Four studies considered time horizons between 12 and 18 months [42, 46, 47, 50], while two studies did not report their time horizon $[40,52]$. Furthermore, outcomes were generally expressed in QALYs $(n=7)$, hip fractures prevented $(n=4)$ or a combination of both $(n=2)$. One study reported their outcomes as lifetime absolute risk reduction of fracture per person [48].

\section{Methodological quality}

Table 2 represents the individual quality assessment results per study, and Fig. 2 gives an overview of total scoring per criteria. Five studies received 100 points [41, 44, 49, 51, 54], which reflect the highest possible QHES score [39]. Another eight studies $[42,43,45-48,50,53]$ reached scores above 75 , indicating high quality studies [39]. In addition, one study [52] had 73 points indicating fair quality, and another study [40] had 30 points indicating poor quality [39]. The last study with the lowest methodological quality according to the QHES criteria was the first economic evaluation study on hip protectors published in 2000 [40]. Within this study, several major shortcomings regarding the methodology for evaluation of the cost-effectiveness analyses were identified, and only 5 out of the 16 criteria were reported.

Furthermore, the majority of QHES criteria (i.e. criteria 1$5,7,9-11,13-15)$ were reported in at least $75 \%$ of the included studies. In at least $25 \%$ of the studies, incremental analysis was not performed (i.e. 4 studies); there was no disclosure regarding the statement of funding described (i.e. 4 studies); the economic model, study methods and analysis not clearly or transparent displayed (i.e. 4 studies), or no adequate analytic time-horizon chosen or discounting used (i.e. 6 studies). The studies Van Schoor et al. and Meyer et al. received poor scores on the last two criteria, basically due to the trial-based study methodology $[46,47]$. The time horizons in these studies were short and therefore also no discounting was performed. Furthermore, due to the trial based methodology, no additional economic model was used. 


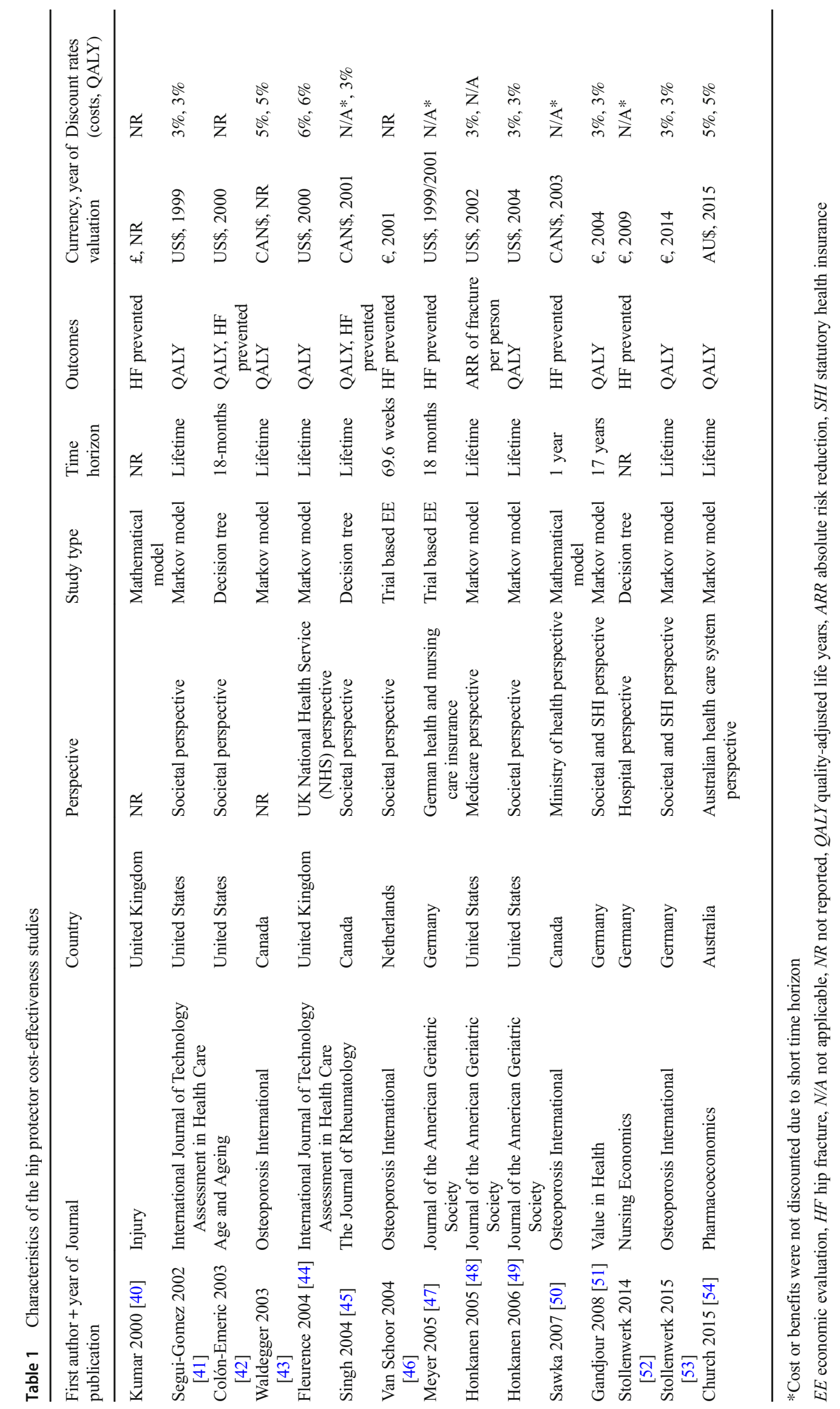




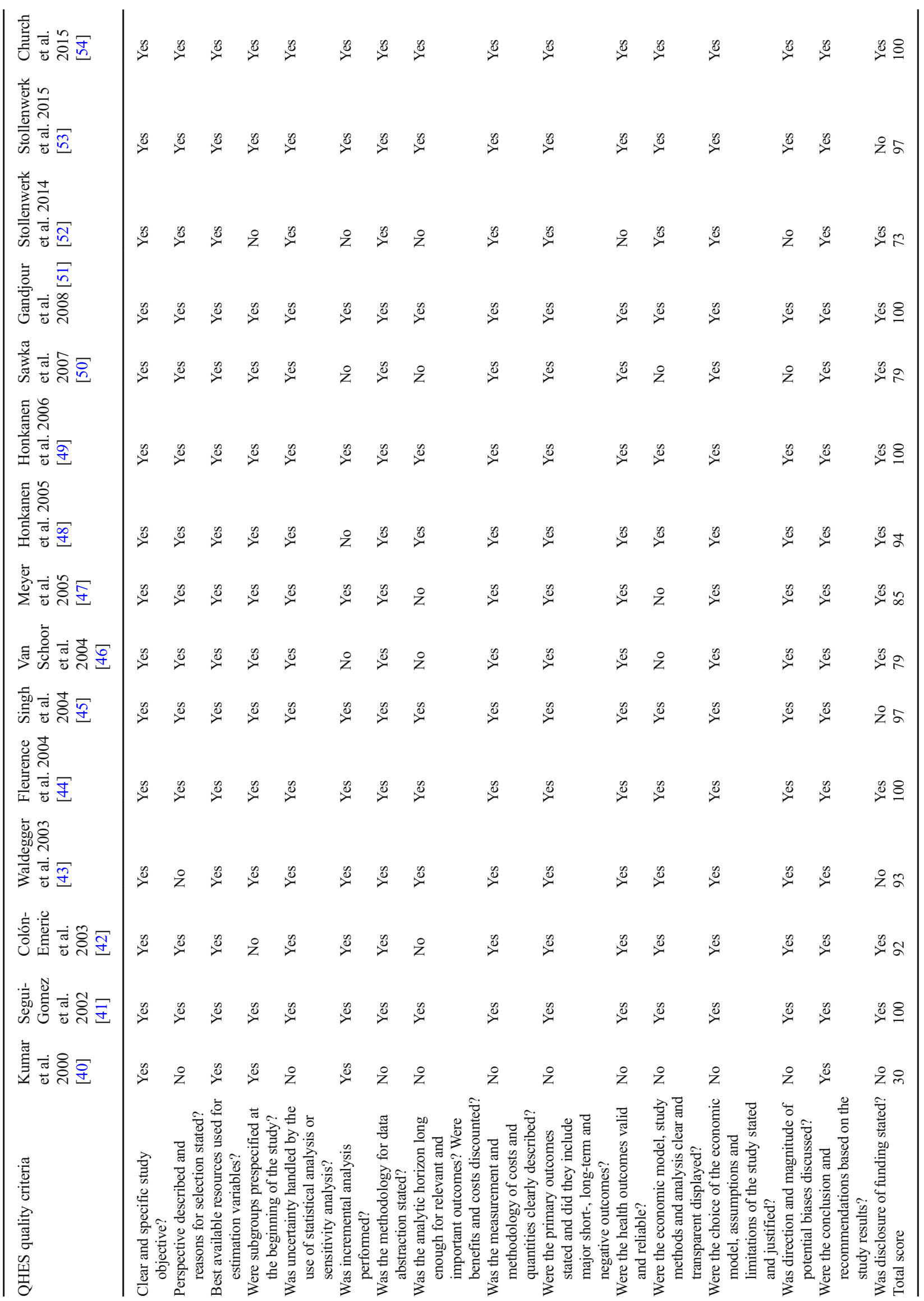


Fig. 2 Quality of reporting of the hip protector cost-effectiveness studies per QHES item

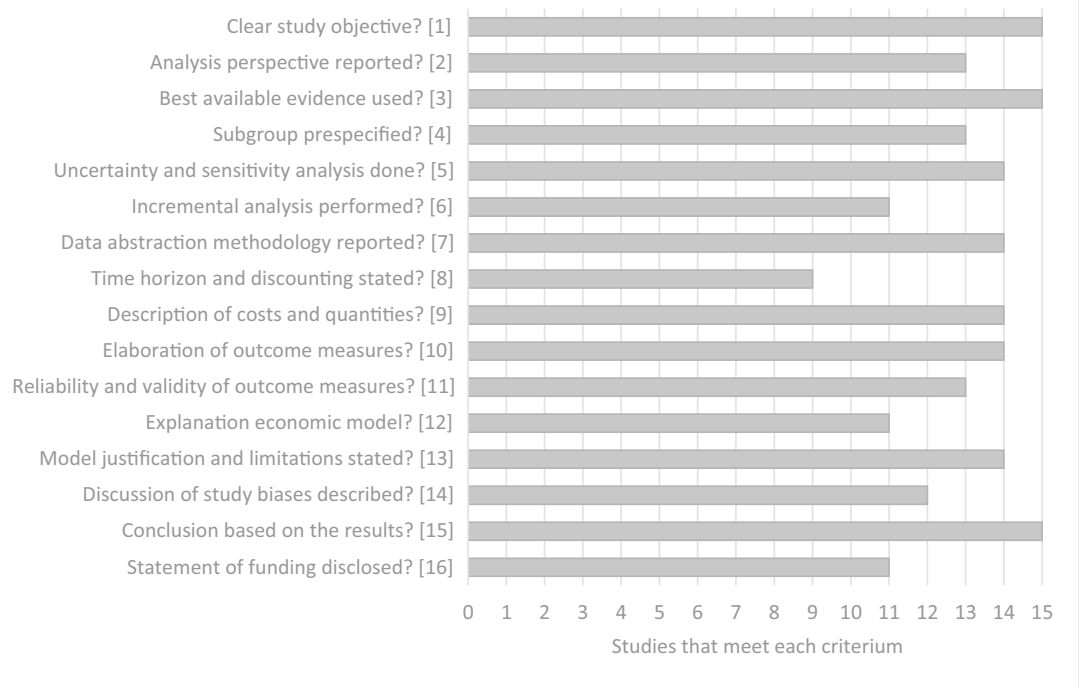

\section{Synthesis of results}

In Table 3, the main outcome results of the individual economic evaluation studies are reported. The hip protector was solely evaluated in three studies $[40,48,50]$ and within 12 other studies compared with no intervention. In three studies, also the effect of other interventions was studied as an addition (i.e. drugs, medication review, multifactorial intervention) [44, $45,54]$. Since this was outside the scope of the current study, only the results of the hip protector compared to no intervention were included in this systematic review. The patient population was a mix of males and females in nearly all studies, although three studies reported specifically a female predominance (ranging from 69.25 to $90.9 \%$ ) [46, 47, 53]. Waldegger et al. evaluated the hip protector solely in females [43]. Moreover, several residence situations were investigated. Eight studies were performed within a long-term care facility also referred to as nursing home, institutional care or residential aged care facilities. Four studies used a combined population of community-dwelling and nursing home residents [40, $44,46,49]$. Stollenwerk et al. examined in two separate studies the use of hip protector in a geriatric hospital setting [52, 53]. Finally, one study did not report information regarding the residence situation of their population [41].

\section{Economic evaluation in long-term care facilities}

The eight studies that investigated the cost-effectiveness in long-term care facilities [42, 43, 45, 47, 48, 50, 51, 54] revealed that the hip protector is a cost-effective intervention for the prevention of hip fractures in males and females, living in long-term care facilities. Age of the residents ranges from 65 to 85 years old, in the included economic evaluation studies. In four of these studies, the use of hip protectors was even found to be dominant (i.e. better outcomes, lower costs) over no intervention, meaning that the hip protector prevented fractures from occurring, which subsequently lead to cost savings as a consequence $[42,43,45,51]$. One of these four studies, Gandjour et al. concluded that hip protector use was a dominant strategy irrespectively of the used perspective (i.e. societal or statutory health insurance perspective) [51]. However, Sawka et al. described that inclusion of the additional labour expenditures, with associated extra costs for application of the hip protector, made cost-savings unlikely [50].

\section{Economic evaluation within a combined population of community and long-term care residents}

Four studies combined community-dwelling residents and residents living in a long-term care facility in their study [40, 44, 46, 49]. Cost-effectiveness was observed in three studies using different cost-effectiveness thresholds [40, 44, 49]. Using a general accepted threshold of $\$ 50,000$ per QALY [55], Fleurence et al. observed cost-effectiveness in males and females aged 70 year and older [44]. Furthermore, costeffectiveness was greater in individuals with a previous hip fracture (i.e. high risk population) compared with the ones without (i.e. general population). Independent from medical history, hip protector use was dominant in females. Honkanen et al. (2006) suggested cost-effectiveness of hip protectors in females aged 75 year and older and in males aged 85 years and older [49]. Kumar et al. reported cost-effectiveness in females aged 80 years and males aged 85 years and older and for residents living in an long-term care facility by using the arbitrary threshold of $£ 7200$ that corresponded with the average cost of treating a hip fracture [40]. However, Van Schoor et al. observed a comparable treatment effect in the hip protector group (i.e. 18 fractures in 276 individuals) compared with no intervention (i.e. 20 fractures in 285 individuals) in their trial based economic evaluation [46]. Furthermore, the 


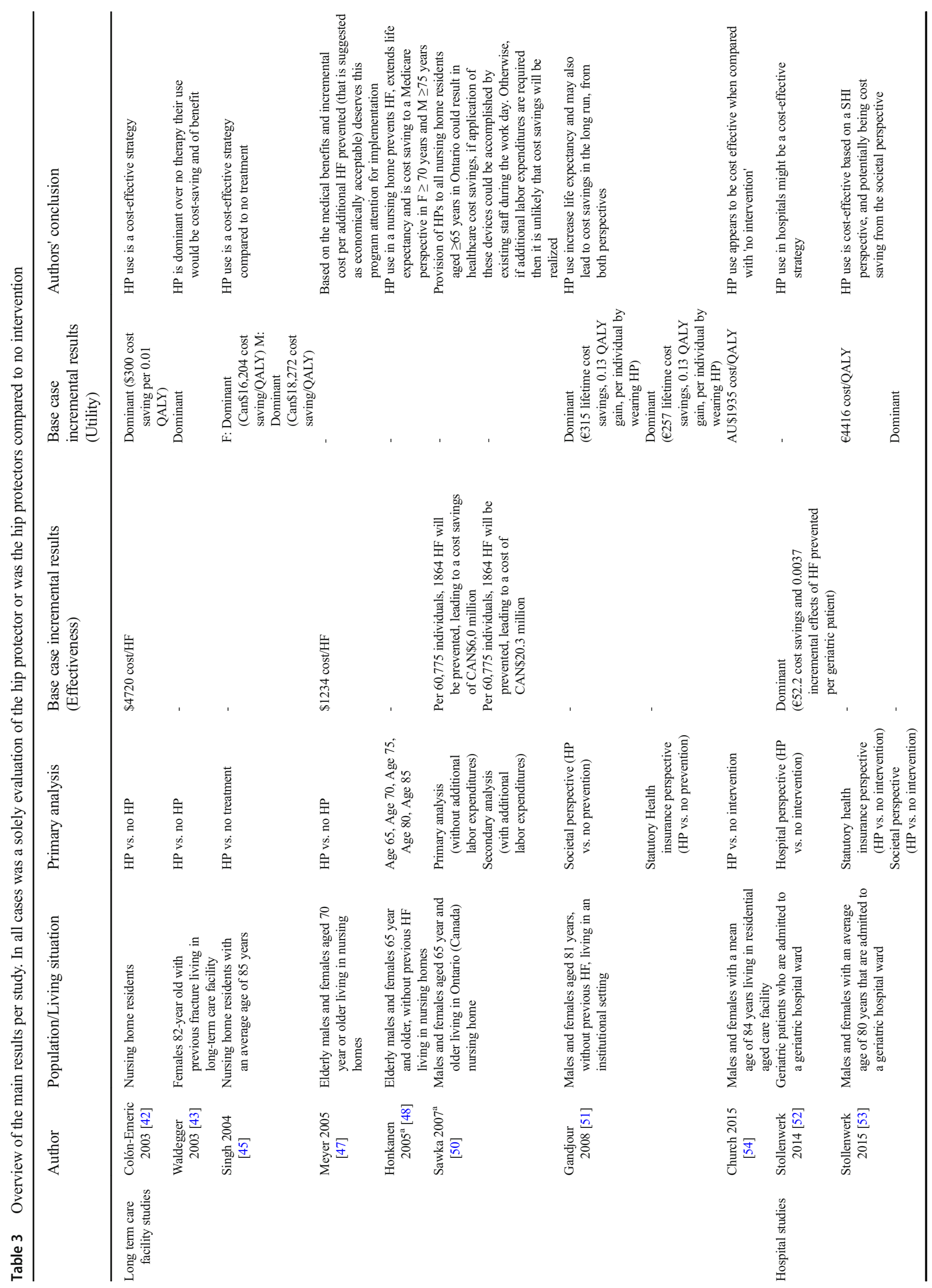




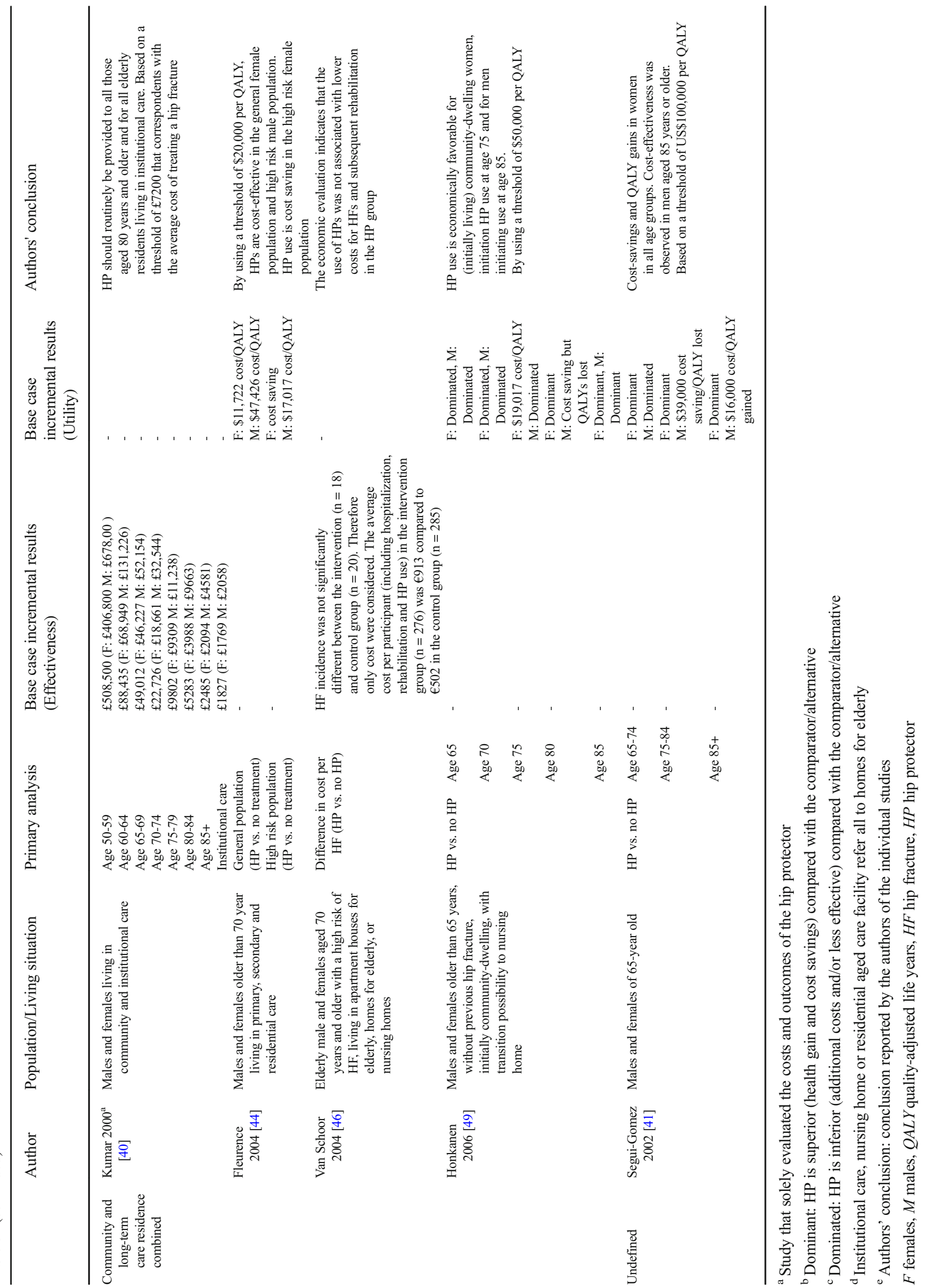


average costs per participant was $€ 411$ higher in the hip protector group $(n=276)$ compared with the control group $(n=$ 285 ), and therefore, the use of hip protectors was not associated with lower costs.

\section{Economic evaluation within a hospital}

Stollenwerk et al. examined in two studies the use of hip protectors in a geriatric ward of a German hospital [52, 53]. Admitted patients received a hip protector during their inhospital stay of on average 15.4 days. The hospital, statutory health insurance (SHI) and societal perspective were considered, and in all scenarios was the hip protector a cost-effective strategy.

\section{Economic evaluation within an undefined residence situation}

Only Segui-Gomez et al. did not report information regarding the residence situation of their cohort [41]. However, the hip protector was a dominant strategy in females aged 65 years and older and a cost-effective strategy in males aged over 85 years based on a threshold of $\$ 100,000$ per QALY.

\section{Discussion}

This systematic review identified 15 economic evaluation studies of hip protectors for the prevention of hip fractures and suggests that hip protectors are a cost-effective approach for the prevention of hip fractures in high-risk populations. First, in all studies, hip protectors have shown to be a costeffective strategy for elderly living within a long-term care facility. Second, wearing of a hip protector in a geriatric ward of a hospital, where patients admitted to a hospital have the highest risk of a fall, might also be a cost-effective strategy. However, more variability regarding cost-effectiveness was observed within studies that combined community-dwelling and long-term care facility residents. Of those studies, three observed cost-effectiveness in males and females although at different ages ranging between 70 to 85 years old across the studies [40, 44, 49]. One study did not observe costeffectiveness at all [46].

To the best of our knowledge, this is the first systematic review that includes and evaluates all available economic studies regarding hip protector use in a standardized and systematic way. Conclusions of some of the individual hip protector cost-effectiveness studies were reported in various studies $[23,31,56,57]$. However, solely evaluation of the hip protector, with extensive overview of the individual study results, systematic comparison and quality assessment of the studies, was not previously done. Therefore this study present an overview of the main outcomes and conclusions used in each of the individual studies, instead of solely reporting cost- effectiveness conclusions [58]. Furthermore, another strength of this study was the use of the QHES quality assessment tool for assessment of the methodological quality of the health economic evaluation studies, since this is a validated tool that enables to gain insights in the quality of an economic evaluation study in a reliable fashion [37-39].

Despite comparable results between various cost-effectiveness studies, some limitations have to be acknowledged. First, an important difference was the hip protector effectiveness for prevention of hip fractures that varied between the economic evaluation studies from 18 to $75 \%$ compared with no intervention [44, 53]. Some of the included studies [40, 41, 48, 52] used randomized control trials [59-62], while others [42, 44, $51,53,54]$ based their effectiveness on extensive systematic reviews [23, 31-33] whereas another group of studies [43, 45, 49] estimated the hip protector effectiveness by combining results of several studies. However, hip protector effectiveness remains an ongoing topic of debate and is highly discussed previously [23, 30-34]. The most recent Cochrane systematic review reported that effectiveness was overestimated in studies until 2001 [23]. For instance, studies reported effectiveness rates between 53 and 67\% [59-61]; however, various methodological issues and reasons were discussed in previous published literature leading to such high effectiveness rates [23, 63]. Currently, the most recent Cochrane systematic review from Santesso et al. [23], which was an update of previous published systematic reviews [31-33], reported a risk ratio (RR) within a long-term care facility of RR 0.82 (range 0.67 to 1.00 ) indicating $18 \%$ reduction of hip fractures by the use of a hip protector [23]. No significant effects were observed by providing hip protectors to the community [23]. A drawback of the included economic evaluation studies published before 2008 is that those studies applied risk reductions that were most likely estimated too high (i.e. 43 to $75 \%$ ) [40-45, 48-50]. Based on the current insights on hip protector effectiveness, previous studies probably overestimated the hip protector effectiveness, leading to overestimated cost-effectiveness levels. However, more recent cost-effectiveness analyses that used the current, more realistic and thus lower estimations for effectiveness rates (i.e. 18 to $23 \%$ ) as reported in updated systematic reviews of 2006, 2010 and 2014 [23, 31, 33], still concluded that hip protector use was a cost-effective intervention in the prevention of hip fractures in long-term care facilities and geriatric hospitals wards [51, 53, 54].

Second, adherence is a key factor that influences hip protector effectiveness as reported by previous published studies [30, 35]. Adherence was reported and taken into account in various modelling studies with levels varying from 25 to $100 \%$ [40, 41, 43-45, 48, 50-52]. In some studies, adjustments were made for clinical effectiveness and QALY decrements taken into account due to the discomfort and inconvenience of the hip protector [41, 49, 53]. The most realistic estimation of adherence to the hip 
protector is still unclear $[23,29,30,35]$. An increase in adherence might lead to a considerable increase of hip protector effectiveness $[29,30,35]$. Several recommendations are described such as improvements in comfort and ergonomics, promotion of hip protectors at institutional level rather than at community level and motivation and education of staff leading to a more interdisciplinary approach $[29,30,35]$.

Third, besides differences between studies regarding input parameters such as, clinical effectiveness and adherence to the therapy, some variability exists between assumptions and choices made in the methodology, which subsequently impacts cost-effectiveness as well. For instance, the societal and third party payer perspectives were the most frequently used perspectives within the economic evaluation studies, whereas the societal perspective is a broad approach that incorporates all types of costs related to the health care interventions (e.g. health care costs, rehabilitation costs) and other non-health related costs (e.g. costs related to productivity losses at work), while a third party perspective or payer perspective only includes costs related to the health care sector (i.e. medical costs) [64, 65]. However, the chosen perspective was not directly related to the conclusions of the individual studies since comparable results on cost-effectiveness were found despite the differences in cost perspective. Despite the differences in perspectives stated, also differences existed in the costs that were considered in a certain defined perspective. For instance, rehabilitation costs were not included in two studies that used a societal perspective [41, 45], while most others with the same perspective did include these in their costs calculations [42, 46, 49, 51, 53]. However, besides the variability in included costs, cost-effectiveness was observed in most of the individual studies. In addition, the effects and costs of additional nursing time related to the application and use of the hip protector in a long-term care facility has yet to be investigated since Sawka et al. found that inclusion of these costs leads to disappearance of cost savings [50]. This was based on an addition of 5 minutes to the total daily nursing time for daily application and removal of the hip protectors, which would lead to a yearly cost of $\$ 413$ for application of the hip protector for one resident. These extra costs, seem to be overestimated and not directly necessary since application and removal can be performed in the same time when a patient will change their regular clothes or underwear.

Fourth, another driver of costs that varied between studies was the amount of hip protectors that was needed per person and the related annual replacements. In most studies, 3 to 4 hip protectors per person per year were considered as a realistic amount [40, 42, 45, 47, 48, 50, 54], while all amounts between 1 to 7 hip protectors per person per year have been used in other studies [41, 43, 44, 49]. Also no universal cost-price per hip protector was reported, but different prices per study. The total annual costs varied between \$50 US dollars and \$322 Canadian dollars (\$244 US dollars) [41, 43]. In summary, heterogeneity between the studies exists, but costeffectiveness of the hip protector for the prevention of hip fractures was observed in nearly all studies.

Next to the heterogeneity, a limited number of studies in community-dwelling residents were identified. Only four studies investigated both community-dwelling and long-term care residents in their study, whereas only the study of Kumar et al. analysed these groups individually [40]. In the other studies, community-dwelling and nursing home residents were not individually analysed and therefore no solely evaluation of this group was available [44, 46, 49]. Thereby, Kumar et al. was the first cost-effectiveness study regarding the use of hip protector. Within this study, major methodological shortcomings were observed, which is also reflected by the low QHES score of 30 indicating poor methodological quality [39]. Furthermore, Van Schoor et al. was the only study who did not observe cost-effectiveness in the mixed population of community-dwelling and long-term care residents. However, in this trial-based study was no statistical significant difference in the incidence of hip fractures observed between the groups with and without hip protectors. Therefore, only cost were evaluated, which are estimated to be higher in the hip protector group, since such protectors have to be purchased and annually replaced. Furthermore, this was a trial based economic evaluation, with a small mixed cohort, a short followup period on average of 69.6 weeks and was hip protector adherence low compared to other economic evaluation studies. Finally, the two other economic evaluation studies observed cost-effectiveness; however, due to different subgroup analysis, no direct trends were observed [44, 49].

In three of the included economic evaluation studies, hip protectors were also compared with vitamin $\mathrm{D}$ and/or calcium supplementation besides the 'no intervention' comparison [44, 45, 54]. Fleurence et al. and Singh et al. observed that hip protectors were a superior costeffective intervention for the prevention of hip fractures compared with vitamin $\mathrm{D}$ and calcium supplementation [44, 45]. However, Church et al. observed the opposite and suggested that vitamin $\mathrm{D}$ was a superior costeffective intervention compared to hip protector use [54]. A reasonable possible explanation for these differences could be the previous discussed clinical effectiveness rates. Fleurence et al. and Singh et al. published in 2004 used more optimistic effectiveness rates compared with the study of Church et al. published in 2015 .

Previously published clinical research has suggested that multifactorial interventions in long-term care facilities might be more beneficial than single interventions alone [63, 66, 67]. Multifactorial interventions could be combinations of, environmental adaptation, resistance training, balance exercises, provision of hip protectors and supplementation with calcium 
and/or vitamin $\mathrm{D}$ or other drugs for treatment of osteoporosis $[66,68]$. Therefore, combinations of the (cost-effective) hip protector and other cost-effective preventive strategies (e.g. drugs) could be interesting options and needs to be further investigated [69]. Müller et al. is currently the only costeffectiveness study that examined a multifactorial fall prevention program including the hip protector within a long-term care facility [68]. The program included education, exercises offered in groups, a hip protector and assessment of personal surroundings of a resident in a nursing home. This multifactorial fall prevention program resulted in a cost-effectiveness ratio of $€ 21,353$ per QALY compared to no fall prevention, indicating that a multifactorial facture prevention program might be a cost-effective intervention for fracture prevention in long-term care facilities [68]. Other combinations such as vitamin $\mathrm{D}$ and/or calcium supplements and the hip protector in a long-term care facilities have to be investigated. Further research is recommended in order to obtain the most costeffective multifactorial prevention program.

In conclusion, this systematic review suggests that hip protectors are a cost-effective approach in the prevention of hip fractures for elderly living within a long-term care facility or admitted to a geriatric ward of a hospital. No weighted conclusion regarding cost-effectiveness can be drawn regarding community-dwelling residents. Future studies towards community-dwelling populations that stratifies for age and gender as well as other potential risk factors (e.g. comorbidities, previous fractures, body mass index) are needed in the specification of community-dwelling patient populations that may benefit from the hip protector and in which of these patients it may be a cost-effective intervention.

\section{Compliance with ethical standards}

Conflict of interest None.

\section{References}

1. Sözen T, Ozisik L, Basaran NC (2017) An overview and management of osteoporosis. Eur J Rheumatol 4(1):46-56

2. Hernlund E, Svedbom A, Ivergard M, Compston J, Cooper C, Stenmark J, McCloskey EV, Jönsson B, Kanis JA (2013) Osteoporosis in the European Union: medical management, epidemiology and economic burden. A report prepared in collaboration with the international osteoporosis foundation (IOF) and the european federation of pharmaceutical industry associations (EFPIA). Arch Osteoporos 8(136):1-115

3. Burge R, Dawson-Hughes B, Solomon DH, Wong JB, King A, Tosteson A (2007) Incidence and economic burden of osteoporosis-related fractures in the United States, 2005-2025. J Bone Miner Res 22(3):465-475

4. Grisso JA, Kelsey JL, Strom BL, Chiu GY, Maislin G, O'Brien LA, Hoffman S, Kaplan F (1991) Risk factors of falls as a cause of hip fracture in women. N Engl J Med 324(19)
5. Braithwaite RS, Col NF, Wong JB (2003) Estimating hip fracture morbidity, mortality and costs. J Am Geriatri Soc 51(3):364-370

6. Keene GS, Parker MJ, Pryor GA (1993) Mortality and morbidity after hip fractures. BMJ. 307(6914):1248-1250

7. Haentjes P, Magaziner J, Colon-Emeric CS, Vanderschueren D, Milisen K, Velkeniers B, Boonen S (2010) Meta-analysis: excess mortality after hip fracture among older women and men. Ann Intern Med 152(6):380-390

8. Cummings SR, Melton LJ (2002) Epidemiology and outcomes of osteoporotic fractures. Lancet. 359(9319):1761-1767

9. Veldman HD, Heyligers IC, Grimm B, Boymans TA (2017) Cemented versus cementless hemiarthroplasty for a displaced fracture of the femoral neck: a systematic review and meta-analysis of current generation hip stems. Bone Joint J 99-B(4):421-431

10. Cooper C, Campion G, Melton LJ (1992) Hip fractures in the elderly: a world wide projection. Osteoporos Int 2(6):285-289

11. Johnell O, Gullberg B, Allander E, Kanis JA, Group MS (1992) The apparent incidence of hip fracture in Europe: a study of national register sources. Osteoporos Int 2(6):298-302

12. Cummings SR, Nevitt MC, Browner WS, Stone K, Fox KM, Ensrud KE, Cauley J, Black D, Vogt TM (1995) Risk factors for hip fracture in white women. Study of osteoporotic fractures research group. N Engl J Med 332(12):767-773

13. Marshall D, Johnell O, Wedel H (1996) Meta-analysis of how well measures of bone mineral density predict occurrence of osteoporotic fractures. BMJ. 312(7041):1254-1259

14. Kanis J, Johnell O, Gullberg B, Allander E, Elffors L, Ranstam J, Dequeker J, Dilsen G, Gennari C, Vaz AL, Lyritis G, Mazzuoli G, Miravet L, Passeri M, Perez Cano R, Rapado A, Ribot C (1999) Risk factors for hip fracture in men from southern Europe: the MEDOS study. Mediterranean osteoporosis study. Osteoporos Int 9(1):45-54

15. Johnell O, Gullberg B, Kanis JA, Allander E, Elffors L, Dequeker J, Dilsen G, Gennari C, Lopes Vaz A, Lyritis G (1995) Risk factors for hip fracture in European women: the MEDOS study. Mediterranean osteoporosis study. J Bone Miner Res 10(11):1802-1815

16. Rubenstein LZ (2006) Falls in older people: epidemiology, risk factors and strategies for prevention. Age Ageing 35 Suppl 2:ii37ii41

17. Finsterwald M, Sidelnikov E, Orav EJ, Dawson-Hughes B, Theiler R, Egli A, Platz A, Simmen HP, Meier C, Grob D, Beck S, Stähelin HB, Bischoff-Ferrari HA (2014) Gender-specific hip fracture risk in community-dwelling and institutionalized seniors age 65 years and older. Osteoporos Int 25(1):167-176

18. Sugarman JR, Connell FA, Hansen A, Helgerson SD, Jessup MC, Lee H (2002) Hip fracture incidence in nursing home residents and community-dwelling older people, Washington State, 1993-1995. J Am Geriatr Soc 50(10):1638-1643

19. Kannus P, Sievanen H, Palvanen M, Järvinen T, Parkkari J (2005) Prevention of falls and consequent injuries in elderly people. Lancet. 366(9500):1885-1893

20. Gass M, Dawson-Hughes B (2006) Preventing osteoporosis-related fractures: an overview. Am J Med 119(4 Suppl 1):S3-S11

21. Riggs BL, Melton LJ 3rd (1992) The prevention and treatment of osteoporosis. N Engl J Med 327(9):620-627

22. Howe TE, Shea B, Dawson LJ, Downie F, Murray A, Ross C, Harbour RT, Caldwell LM, Creed G (2011) Exercise for preventing and treating osteoporosis in postmenopausal women. Cochrane Database Syst Rev 7:CD000333

23. Santesso N, Carrasco-Labra A, Brignardello-Petersen R (2014) Hip protectors for preventing hip fractures in older people. Cochrane Database Syst Rev 3:CD001255

24. Cumming RG, Klineberg RJ (1994) Case-control study of risk factors for hip fractures in the elderly. Am J Epidemiol 139(5):493503 
25. Cummings SR, Kelsey JL, Nevitt MC, O'Dowd KJ (1985) Epidemiology of osteoporosis and osteoporotic fractures. Epidemiol Rev 7:178-208

26. van Schoor NM, van der Veen AJ, Schaap LA, Smit TH, Lips P (2006) Biomechanical comparison of hard and soft hip protectors, and the influence of soft tissue. Bone. 39(2):401-407

27. Laing AC, Robinovitch SN (2008) Effect of soft shell hip protectors on pressure distribution to the hip during sideways falls. Osteoporos Int 19(7):1067-1075

28. Minns RJ, Marsh AM, Chuck A, Todd J (2007) Are hip protectors correctly positioned in use? Age Ageing 36(2):140-144

29. Cianferotti L, Fossi C, Brandi ML (2015) Hip protectors: are they worth it? Calcif Tissue Int 97(1):1-11

30. Cameron ID, Robinovitch S, Birge S, Kannus P, Khan K, Lauritzen J, Howland J, Evans S, Minns J et al (2010) Hip protectors: recommendations for conducting clinical trials-an international consensus statement (part II). Osteoporos Int 21(1):1-10

31. Gillespie WJ, Gillespie LD, Parker MJ (2010) Hip protectors for preventing hip fractures in older people. Cochrane Database Syst Rev 10:CD001255

32. Parker MJ, Gillespie LD, Gillespie WJ (2003) Hip protectors for preventing hip fractures in the elderly. Cochrane Database Syst Rev 3:CD001255

33. Parker MJ, Gillespie WJ, Gillespie LD (2006) Effectiveness of hip protectors for preventing hip fractures in elderly people: systematic review. BMJ. 332(7541):571-574

34. Oliver D, Connelly JB, Victor CR, Shaw FE, Whitehead A, Genc Y, Vanoli A, Martin FC, Gosney MA (2007) Strategies to prevent falls and fractures in hospitals and care homes and effect of cognitive impairment: systematic review and meta-analyses. BMJ. 334(7584):82

35. Korall AM, Feldman F, Scott VJ, Wasdell M, Gillan R, Ross D, Thompson-Franson T, Leung PM, Lin L (2015) Facilitators of and barriers to hip protector acceptance and adherence in longterm care facilities: a systematic review. J Am Med Dir Assoc 16(3):185-193

36. Moher D, Liberati A, Tetzlaff J, Altman DG (2009) Preferred reporting items for systematic reviews and meta-analyses: the PRISMA statement. PLoS Med 6(7):1-6

37. Ofman JJ, Sullivan SD, Neumann PJ, Chiou CF, Henning JM, Wade SW, Hay JW (2003) Examining the value and quality of health economic analyses: implications of utilizing the QHES. J Manag Care Pharm 9(1):53-61

38. Chiou CF, Hay JW, Wallace JF, Bloom BS, Neumann PJ, Sullivan SD, Yu HT, Keeler EB, Henning JM, Ofman JJ (2003) Development and validation of a grading system for the quality of cost-effectiveness studies. Med Care 41(1):32-44

39. Spiegel BM, Targownik LE, Kanwal F, Derosa V, Dulai GS, Grainek IM, Chlou CF (2004) The quality of published health economic analyses in digestive diseases: a systematic review and quantitative appraisal. Gastroenterology. 127(2):403-411

40. Kumar BA, Parker MJ (2000) Are hip protectors cost effective? Injury. 31(9):693-695

41. Segui-Gomez M, Keuffel E, Frick KD (2002) Cost and effectiveness of hip protectors among the elderly. Int J Technol Assess Health Care 18(1):55-66

42. Colon-Emeric CS, Datta SK, Matchar DB (2003) An economic analysis of external hip protector use in ambulatory nursing facility residents. Age Ageing 32(1):47-52

43. Waldegger L, Cranney A, Man-Son-Hing M, Coyle D (2003) Costeffectiveness of hip protectors in institutional dwelling elderly. Osteoporos Int 14(3):243-250
44. Fleurence RL (2004) Cost-effectiveness of fracture prevention treatments in the elderly. Int J Technol Assess Health Care 20(2): 184-191

45. Singh S, Sun H, Anis AH (2004) Cost-effectiveness of hip protectors in the prevention of osteoporosis related hip fractures in elderly nursing home residents. J Rheumatol 31(8):1607-1613

46. van Schoor NM, de Bruyne MC, van der Roer N, Lommerse E, van Tulder MW, Bouter LM, Lips P (2004) Cost-effectiveness of hip protectors in frail institutionalized elderly. Osteoporos Int 15(12): 964-969

47. Meyer G, Wegscheider K, Kersten JF, Icks A, Muhlhauser I (2005) Increased use of hip protectors in nursing homes: economic analysis of a cluster randomized, controlled trial. J Am Geriatr Soc 53(12): 2153-2158

48. Honkanen LA, Schackman BR, Mushlin AI, Lachs MS (2005) A cost-benefit analysis of external hip protectors in the nursing home setting. J Am Geriatr Soc 53(2):190-197

49. Honkanen LA, Mushlin AI, Lachs M, Schackman BR (2006) Can hip protector use cost-effectively prevent fractures in communitydwelling geriatric populations? J Am Geriatr Soc 54(11):1658 1665

50. Sawka AM, Gafni A, Boulos P, Beattie K, Papaioannou A, Cranney A, Hanley DA, Adachi JD, Cheung A, Papadimitropoulos EA, Thabane L (2007) Could a policy of provision of hip protectors to elderly nursing home residents result in cost savings in acute hip fracture care? The case of Ontario, Canada. Osteoporos Int 18(6): $819-827$

51. Gandjour A, Weyler EJ (2008) Cost-effectiveness of preventing hip fractures by hip protectors in elderly institutionalized residents in Germany. Value Health 11(7):1088-1095

52. Stollenwerk B, Waldeyer R, Klein-Meding C, Muller D, Stock S (2014) Cost effectiveness of external hip protectors in the hospital setting: a modeling study. Nurs Econ 32(2):89-98

53. Stollenwerk B, Bartmus T, Klug F, Stock S, Muller D (2015) Costeffectiveness of hip protector use on a geriatric ward in Germany: a Markov model. Osteoporos Int 26(4):1367-1379

54. Church JL, Haas MR, Goodall S (2015) Cost effectiveness of falls and injury prevention strategies for older adults living in residential aged care facilities. Pharmacoeconomics. 33(12):1301-1310

55. Cohen DJ, Reynolds MR (2009) Interpreting the results of costeffectiveness studies. J Am Coll Cardiol 52(25):2119-2126

56. Polinder S, Segui-Gomez M, Toet H, Belt E, Sethi D, Racioppi F, van Beeck EF (2012) Systematic review and quality assessment of economic evaluation studies of injury prevention. Accid Anal Prev 45:211-221

57. Gyllensvard H (2010) Cost-effectiveness of injury prevention - a systematic review of municipality based interventions. Cost Eff Resour Alloc 8:17

58. Mastrigt GA, Hiligsmann M, Arts JJ, Broos PH, Kleijnen J, Evers SM, Majoie MH (2016) How to prepare a systematic review of economic evaluations for informing evidence-based healthcare decisions: a five-step approach (part 1/3). Expert Rev Pharmacoecon Outcomes Res 16(6):689-704

59. Chan DK, Hillier G, Coore M, Cooke R, Monk R, Mills J, Hung WT (2000) Effectiveness and acceptability of a newly designed hip protector: a pilot study. Arch Gerontol Geriatr 30(1):25-34

60. Ekman A, Mallmin H, Michaelsson K, Ljunghall S (1997) External hip protectors to prevent osteoporotic hip fractures. Lancet. 350(9077):563-564

61. Kannus P, Parkkari J, Niemi S, Pasanen M, Palvanen M, Jarvinen M, Vuori I (2000) Prevention of hip fracture in elderly people with use of a hip protector. N Engl J Med 343(21):1506-1513 
62. Lauritzen JB, Petersen MM, Lund B (1993) Effect of external hip protectors on hip fractures. Lancet. 341(8836):11-13

63. Cameron ID, Murray GR, Gillespie LD, Robertson MC, Hill KD, Cumming RG, Kerse N (2010) Interventions for preventing falls in older people in nursing care facilities and hospitals. Cochrane Database Syst Rev 1:CD005465

64. Garrison LP Jr, Pauly MV, Willke RJ, Neumann PJ (2018) An overview of value, perspective, and decision context-a health economics approach: an ISPOR special task force report [2]. Value Health 21(2):124-130

65. Strand Bergmo T (2015) How to measure costs and benefits of ehealth interventions: an overview of methods and frameworks. J Med Internet Res 17(11):254

66. Cameron ID, Gillespie LD, Robertson MC, Murray GR, Hill KD, Cumming RG, Kerse N (2012) Interventions for preventing falls in older people in care facilities and hospitals. Cochrane Database Syst Rev 12:CD005465
67. Neyens JC, van Haastregt JC, Dijcks BP, Martens M, van den Heuvel WJ, de Witte LP, Schols JM (2011) Effectiveness and implementation aspects of interventions for preventing falls in elderly people in long-term care facilities: a systematic review of RCTs. J Am Med Dir Assoc 12(6):410-425

68. Muller D, Borsi L, Stracke C, Stock S, Stollenwerk B (2015) Costeffectiveness of a multifactorial fracture prevention program for elderly people admitted to nursing homes. Eur J Health Econ 16(5):517-527

69. Hiligsmann M, Evers SM, Ben Sedrine W, Kanis JA, Ramaekers B, Reginster JY, Silverman S, Wyers CE, Boonen A (2015) A systematic review of cost-effectiveness analyses of drugs for postmenopausal osteoporosis. Pharmacoeconomics. 33(3):205-224

Publisher's note Springer Nature remains neutral with regard to jurisdictional claims in published maps and institutional affiliations. 